$\underline{\text { Artikel Penelitian }}$

\title{
FAKTOR-FAKTOR YANG BERHUBUNGAN DENGAN STRES KERJA PADA PERAWAT DIRUANG RAWAT INAP RUMAH SAKIT UMUM DAERAH NAMROLE
}

Zulfikar Lating ${ }^{1}$, Rislan Soumena ${ }^{1}$

${ }^{1}$ STIKes Maluku Husada

Correspoding author e-mail : fikarlating066@gmail.com

\begin{abstract}
Abstrak
Pendahuluan. Stres kerja merupakan bagian dari permasalahan umum yang sering dijumpai pada tenaga kerja termasuk perawat. Berdasarkan observasi awal yang dilakukan peneliti di RSUD Namrole terhadap 5 orang dari ruang yang berbeda di Unit Ruang Rawat Inap, didapat oleh peneliti bahwa perawat di ruang rawat inap mempunyai cenderung stres kerja. Tujuan. Penelitian ini bertujuan untuk mengetahui hubungan beban kerja, pendidikan terakhir dan masa kerja terhadap stres kerja pada perawat diruang rawat inap RSUD Namrole tahun 2020. Metode. Jenis penelitian ini menggunakan studi analitik dengan pendekatan cross sectional study. Populasi dalam penelitian ini adalah seluruh perawat di ruang rawat inap RSUD Namrole. Teknik pengambilan sampel yakni purposive sampling jumlah sampel sebanyak 60 responden di pilih sesuai kriteria. Metode analisis data menggunakan uji bivariat dan uji kolerasi Chi-square pada tingkat kepercayaan $95 \%(\alpha=0,05)$. Hasil. Dari hasil penelitian di peroleh bahwa ada hubungan beban kerja dengan stres kerja $p=0,000(p<\alpha=0,05)$. Kesimpulan. Ada hubungan Pendidikan dengan stres kerja $p=0,000(p<\alpha=0,05)$. Tidak ada hubungan pendidikan terakhir dengan stres kerja $p=0,459(p>\alpha=0,05)$.
\end{abstract}

Kata Kunci: Stres kerja, beban kerja, pendidikan terakhir, dan masa kerja.

\begin{abstract}
Introduction. Work stress is part of the common problems that are often encountered in the workforce, including nurses. Based on the initial observations made by researchers at the Namrole Hospital on 5 people from different rooms in the Inpatient Room Unit, the researchers found that nurses in the inpatient room tended to be stressed at work. Aim. This study aims to determine the relationship between workload, last education and tenure of work stress on nurses in the inpatient room at Namrole Hospital in 2020. Method. This type of research used an analytical study with a cross sectional study approach. The population in this study were all nurses in the inpatient room at Namrole Hospital. The sampling technique is purposive sampling with a sample of 60 respondents according to the criteria. Data analysis method used bivariate test and Chi-square correlation test at $95 \%$ confidence level $(\alpha=0.05)$. Result. From the research results obtained that there is a relationship between workload and work stress $p=0.000(p<\alpha=0.05)$. There is a relationship between education and work stress $p$ $=0.000(p<\alpha=0.05)$. Conclusion. There is no relationship between the last education and work stress $p=0.459$ $(p>=0.05)$.
\end{abstract}

Keywords: Work stress, workload, last education, and years of service.

\section{Pendahuluan}

Stres kerja merupakan salah satu perhatian utama bagi keselamatan dan kesehatan kerja terhadap tenaga kerja. Stress kerja dapat mempengaruhi pekerja, baik pada masalah dibidang kesejahteraan maupun kesehatan. Telah diperkirakan bahwa sekitar setengah dari semua pekerja absen dalam bekerja diakibatkan oleh gangguan yang berhubungan dengan Stress akibat pekerjaan ${ }^{1}$. Stress juga merupakan suatu respon adaptif, melalui karakteristik individu dan atau proses psikologis secara langsung terhadap tindakan, situasi dan kejadian eksternal yang bersangkutan. Stress juga merupakan kondisi dinamis dimana seorang individu 
dihadapkan dengan kesempatan, keterbatasan atau tuntutan yang tidak sesuai dengan harapan yang ingin dicapai dalam kondisi penting dan tidak menentu ${ }^{2}$

Berdasarkan data World Health Organization (WHO), sekitar 450 juta orang di Dunia mengalami Stres. Hasil penelitian Labour Force Survey pada tahun 2016 menemukan adanya 440.000 kasus Stress akibat kerja di Inggris dengan angka kejadian sebanyak 1.380 kasus per 100.000 pekerja yang mengalami Stress akibat kerja. Sebesar 35\% Stress akibat kerja berakibat fatal dan diperkirakan hari kerja yang hilang sebesar 43\%. Di kawasan Asia Pasifik tren Stress kerja melebihi rata-rata global yang berkisar $48 \%$. Berdasarkan hasil survei Regus pada tahun 2016 yang diperoleh dari CFO Innovation Asia Staff ${ }^{3}$, tingkat Stress kerja di negara-negara seperti Malaysia mencapai 57\%, Hongkong 62\%, Singapura 63\%, Vietnam 71\%, Cina $73 \%$, Indonesia $73 \%$, dan Thailand $75 \%$. Indonesia mengalami peningkatan sebesar 9\% dari tahun sebelumnya yang hanya berada di tingkat $64 \%$. Tingginya persentase Stress kerja di Indonesia, selain dipengaruhi oleh faktor di dalam negeri, juga terkait dengan faktor individu dan pekerjaan ${ }^{4}$.

Kejadian Stress kerja erat kaitannya dengan faktor pekerjaan, seperti jadwal kerja, beban kerja, konflik peran, dan konflik interpersonal, sumber daya manusia merupakan salah satu asset yang menentukan maju mundurnya suatu organisasi. Demikian pula halnya dalam bidang pelayanan kesehatan, khususnya di rumah sakit, tak terlepas dari dampak adanya era globalisasi tersebut ${ }^{5}$.
Rumah sakit sebagai sebuah institusi yang bergerak dalam bidang jasa pelayanan kesehatan telah mengalami beberapa perubahan mendasar. Pada awalnya perkembangan rumah sakit adalah sebuah lembaga yang bersifat sosial. Tetapi dengan masuknya rumah sakit swasta serta pemodal baik yang berasal dari dalam negeri maupun asing, menjadikan rumah sakit lebih mengacu sebagai suatu industri yang bergerak dalam bidang pelayanan kesehatan. Pekerja Kesehatan di rumah sakit sangat bervariasi baik dari segi jenis maupun jumlahnya. Dalam melaksanakan tugasnya, pekerja rumah sakit banyak terpapar dengan berbagai faktor yang dapat menimbulkan dambak negatif dan mempengaruhi derajat kesehatan mereka. Mereka selalu berhubungan dengan baik dan benar berbagai bahaya potensial, dimana bila tidak di antisipasi dengan baik dan benar dapat mempengaruhi kesehatan dan keselamatan kerjanya ${ }^{6}$.

Pekerja rumah sakit yang terbanyak adalah perawat, terdapat sekitar $60 \%$ dari tenaga kesehatan rumah sakit. Perawat merupakan salah satu tenaga kesehatan yang selalu ada di setiap rumah sakit dan merupakan ujung tombak pelayanan kesehatan rumah sakit. Perawat adalah suatu profesi yang mengkhususkan pada upaya penanganan dan perawatan pasien. Fungsi perawat adalah sebagai pemberi asuhan keperawatan dan pendidikan kesehatan kepada pasien baik dalam keadaan sakit maupun sehat dengan tujuan untuk meningkatkan kesejahteraan yang optimal. $^{2}$

Dalam menjalankan fungsinya sebagian besar perawat mengalami stres kerja, maka http://ojs3.unpatti.ac.id/index.php/moluccamed 
dapat mengganggu kinerja rumah sakit karena perawat tidak bisa memberikan pelayanan yang terbaik bagi rumah sakit dan pada akhirnya akan mempengaruhi daya saing mereka di pasar dan lebih dari itu bahkan dapat membahayakan kelangsungan organisasi rumah sakit ${ }^{5}$.

Stres kerja dianggap sebagai salah satu risiko pekerjaan yang paling penting di era modern. Setiap tahun sistem pelayanan kesehatan menghabiskan 200 miliar dolar karena masalah ini. Stres kerja menyebabkan penurunan produktivitas, ketidakhadiran, rotasi staf di bangsal dan tingginya biaya perawatan kesehatan staf ${ }^{6}$. American National Association For Occupational Safety menempatkan kejadian stres pada perawat berada di urutan paling atas pada empat puluh pertama kasus stres pada pekerja ${ }^{7}$. Berdasarkan hasil survei yang dilakukan pada perawat di Swedia diperoleh hasil yaitu lebih dari $80 \%$ perawat mengalami stres yang cukup tinggi akibat pekerjaan ${ }^{8}$. Selain itu penelitian yang dilakukan di Rumah Sakit Umum Provinsi Ratchaburi Thailand, menemukan bahwa 26,2\% perawat di rumah sakit tersebut berada pada kelompok risiko tinggi untuk terkena stres akibat kerja ${ }^{9}$. Di Indonesia, berdasarkan hasil penelitian yang dilakukan oleh ${ }^{10}$, Beban Kerja Perawat Dengan Stres Kerja Pada Perawat Pelaksana Di Ruang Rawat Inap RSUD Dr. Moewardi Surakarta terdapat hubungan bermakna perawat mengalami stres kerja.

Stres telah menjadi salah satu masalah kesehatan yang paling serius karena tidak hanya merugikan dari sisi morbiditas fisik dan juga mental, melainkan juga merugikan pengusaha, pemerintah dan masyarakat luas dari sisi keuangan. Kekhawatiran akan menurunnya kinerja perawat, keberadaan profesi perawat sering dianggap biasa saja, walaupun pada kenyataannya peranan perawat dalam pemeliharaan kesehatan sangat vital. Pada perencanaan kebutuhan tenaga keperawatan, perlu diingat bahwa tuntutan pengguna jasa rumah sakit saat ini berbeda dengan beberapa tahun yang lalu. Pengguna jasa rumah sakit saat ini tidak hanya menuntut kesembuhan, tetapi juga menuntut pelayanan yang cepat, sopan dan ramah. Pihak pasien menuntut sprei harus selalu bersih, meminta spuit dan jarum yang disposable dan mereka harus melihat perawat membukanya dari kemasan utuh. Bahkan perawat yang tidak menggunakan sarung tangan saat bekerja dianggap tidak bonafide ${ }^{11}$.

Rumah Sakit Umum Daerah Kota Namrole adalah rumah sakit yang memberikan pelayanan perawatan kesehatan terhadap masyarakat di Daerah Namrole dan merupakan rumah sakit rujukan bagi puskesmas-puskesmas yang ada di sekitarnya. Unit Perawatan Rawat Inap yang ada di RSUD Daerah Namrole terdiri dari Ruang rawat inap dewasa (17 responden), ruang HCU (12 responden), ruang rawat inap anak (14 responden), ruang rawat inap kebidanan (19 responden), ruang perinatal (3 responden) Berdasarkan data RSUD Namrole (2020) terdapat 65 perawat di Ruang Rawat Inap.

Berdasarkan wawancara awal yang dilakukan peneliti di RSUD Namrole terhadap 5 responden dari ruang yang berbeda-beda di Unit Ruang Rawat Inap, didapat oleh peneliti http://ojs3.unpatti.ac.id/index.php/moluccamed 
bahwa perawat di ruang rawat inap mempunyai cenderung stres kerja. Perawat di ruangan perawatan dituntut untuk dapat melakukan komunikasi pada pasien terutama untuk menyiapkan mental dan rohaninya dalam menghadapi operasi dan setelah operasi, mendorong brankar pasien menuju kamar operasi, mengangkat pasien, merawat luka bekas operasi dan menjaga kebersihan untuk mencegah infeksi pada luka tersebut. Dari latar belakang masalah yang diuraikan tersebut, maka peneliti tertarik untuk mengadakan penelitian yang difokuskan pada masalah faktor yang berhubungan dengan stres kerja pada Perawat di ruang rawat inap Rumah Sakit Umum Daerah namrole dan menuangkannya dalam bentuk skripsi dengan judul Faktor Yang Berhubungan Dengan Stres Kerja Pada Perawat Di Ruang Rawat Inap Rumah Sakit Umum Daerah Namrole.

\section{Metode}

Penelitian ini merupakan jenis studi analitik dengan pendekatan cross sectional study, yaitu mencari faktor yang berhubungan dengan variabel dependen yang diteliti dalam waktu bersamaan. Populasi dalam penelitian ini adalah perawat yang bertugas di rawat inap Rumah Sakit Umum Daerah Namrole yang berjumlah 65 orang. Berdasarkan Data dianalisis secara univariat dan bivariat. Analisis univariat digunakan untuk mengetahui distribusi frekuensi responden seperti usia, jenis kelamin, pendidikan terakhir, masa kerja, beban kerja, denyut nadi dan stress kerja. Analisis bivariat menggunakan analisis chi-square yaitu untuk mencari hubungan antara variabel.

\section{Hasil}

Penelitian dilakukan di Rumah Sakit Umum Daerah Namrole. Penelitian ini berlangsung selama bulan Agustus 2020. Subjek penelitian adalah perawat di Ruang Rawat Inap RSUD Namrole. Dengan sampel 65 orang. Berikut adalah karakteristik responden berdasarkan usia, jenis kelamin, pendidikan terakhir, masa kerja, beban kerja, denyut nadi dan stress kerja.yang dijelaskan dalam bentuk tabel.

Analisis Univariat

Tabel 1 tentang distribusi responden menurut usia di ruang rawat inap RSUD Namrole diketahui bahwa kebanyakan perawat di ruang rawat inap berusia $<30$ tahun sebanyak $71,7 \%$ (43 responden) sedangkan yang berusia $\geq$ 30 tahun sebanyak 28,3\% (17 responden).

Tabel 1. Distribusi Responden Berdasarkan Usia Pada Perawat Di Ruang Rawat Inap RSUD Kota Namrole Tahun 2020

\begin{tabular}{ccc}
\hline \multirow{2}{*}{ Usia } & \multicolumn{2}{c}{ Jumlah } \\
\cline { 2 - 3 } & $\mathbf{n}$ & $\mathbf{\%}$ \\
\hline$<30$ Tahun & 43 & 71,7 \\
$\geq 30$ Tahun & 17 & 28,3 \\
\hline Total & $\mathbf{6 0}$ & $\mathbf{1 0 0}$ \\
\hline
\end{tabular}

Sumber: Data Primer 2020

Tabel 2. Distribusi Responden Berdasarkan Jenis Kelamin Pada Perawat Di Ruang Rawat Inap RSUD Kota Namrole Tahun 2020

\begin{tabular}{ccc}
\hline \multirow{2}{*}{ Jenis Kelamin } & \multicolumn{2}{c}{ Jumlah } \\
& n & \% \\
\hline Laki-Laki & 5 & 8,3 \\
Perempuan & 55 & 91,7 \\
\hline Total & $\mathbf{6 0}$ & $\mathbf{1 0 0}$ \\
\hline
\end{tabular}

Sumber: Data Primer 2020 
Tabel 2 tentang distribusi responden menurut jenis kelamin di ruang rawat inap RSUD Kota Namrole diketahui bahwa kebanyakan perawat di ruang rawat inap yakni perempuan sebanyak 91,7\% (55 responden) dan sisanya adalah lakilaki sebanyak $8,3 \%$ (5 responden).

Tabel 3. Distribusi Responden Berdasarkan Pendidikan Terakhir Pada Perawat Di Ruang Rawat Inap RSUD Kota Namrole Tahun 2020

\begin{tabular}{ccc}
\hline \multirow{2}{*}{ Pendidikan } & Jumlah & $\mathbf{n}$ \\
\hline SMA/SPK & 22 & 36,7 \\
DIII & 5 & 8,3 \\
S1 & 23 & 38,3 \\
Ners & 10 & 16,7 \\
\hline Total & $\mathbf{6 0}$ & $\mathbf{1 0 0}$ \\
\hline
\end{tabular}

Sumber: Data Primer 2020

Tabel 3 tentang distribusi responden menurut pendidikan terakhir di ruang rawat inap RSUD Kota Namrole diketahui bahwa kebanyakan perawat di ruang rawat inap pendidikan terakhirnya SMA/SPK sebanyak 36,7\% (22 responden), untuk DIII sebanyak 8,3\% (5 responden), S1 sebanyak 38,3\% (23 responden) dan Ners sebanyak 16,7\% (10 responden).

Tabel 4. Distribusi Responden Berdasarkan Masa Kerja Pada Perawat di Ruang Rawat Inap RSUD Kota Namrole Tahun 2020

\begin{tabular}{ccc}
\hline Masa Kerja & Jumlah & n \\
\hline Lama & 30 & 50 \\
Baru & 30 & 50 \\
\hline Total & $\mathbf{6 0}$ & $\mathbf{1 0 0}$ \\
\hline
\end{tabular}

Sumber: Data Primer 2020

Tabel 4 tentang distribusi responden menurut masa kerja di ruang rawat inap RSUD Kota Namrole diketahui bahwa perawat di ruang rawat inap yang telah lama bekerja sebanyak
$30 \%$ (50 responden) dan yang baru bekerja sebanyak 30\% (50 responden).

Tabel 5. Distribusi Responden Berdasarkan Beban Kerja Pada Perawat di Ruang Rawat Inap RSUD Kota Namrole Tahun 2020

\begin{tabular}{ccc}
\hline \multirow{2}{*}{ Beban kerja } & \multicolumn{2}{c}{ Jumlah } \\
\cline { 2 - 3 } & $\mathbf{n}$ & $\mathbf{\%}$ \\
\hline Ringan & 23 & 38.3 \\
Sedang & 15 & 25.0 \\
Berat & 22 & 36.7 \\
\hline Total & $\mathbf{6 0}$ & $\mathbf{1 0 0}$ \\
\hline
\end{tabular}

Sumber: Data Primer 2020

Tabel 5 dari hasil di atas tentang variable beban kerja tentang distribusi responden menurut beban kerja di ruang rawat inap RSUD Kota Namrole diketahui bahwa perawat di ruang rawat inap yang mengalami beban kerja ringan sebanyak $38.3 \%$ (23 responden) dan yang beban kerjanya sedang sebanyak $25.0 \%$ responden) dan beban kerjanya berat sebanyak $36.7 \%$ (22 responden).

Tabel 6 tentang distribusi responden menurut denyut nadi di ruang rawat inap RSUD Kota Namrole diketahui bahwa perawat di ruang rawat inap kebanyakan memiliki denyut nadi $\leq$ 100 sebanyak 38,3\% (23 responden) dan yang denyut nadinya $>100$ sebanyak 61,7\% (37 responden).

Tabel 6. Distribusi Responden Berdasarkan Denyut Nadi Pada Perawat di Ruang Rawat Inap RSUD Kota Namrole Tahun 2020

\begin{tabular}{ccc}
\hline \multirow{2}{*}{ Denyut Nadi } & \multicolumn{2}{c}{ Jumlah } \\
\cline { 2 - 3 } & $\mathbf{n}$ & $\mathbf{\%}$ \\
\hline$\leq 100$ & 23 & 38,3 \\
$>100$ & 37 & 61,7 \\
\hline Total & $\mathbf{6 0}$ & $\mathbf{1 0 0}$ \\
\hline
\end{tabular}

Sumber: Data Primer 2020

Tabel 7. Distribusi Responden Berdasarkan Stres Kerja Pada Perawat Di Ruang Rawat Inap RSUD Kota Namrole Tahun 2020

\begin{tabular}{ccc}
\hline \multirow{2}{*}{ Stres Kerja } & \multicolumn{2}{c}{ Jumlah } \\
\cline { 2 - 3 } & n & \% \\
\hline Rendah & 18 & 30.0
\end{tabular}




\begin{tabular}{ccc} 
Sedang & 24 & 40.0 \\
Berat & 18 & 30.0 \\
\hline Total & $\mathbf{6 0}$ & $\mathbf{1 0 0}$
\end{tabular}

Sumber: Data Primer 2020

Tabel 7 tentang distribusi responden menurut stres kerja di ruang rawat inap RSUD Kota Namrole diketahui bahwa perawat di ruang rawat inap dengan stres kerja Rendah sebanyak 30.0\% (18 responden) dan stres kerja Sedang sebanyak $40.0 \%$ (24 responden) dan stres kerja Berat sebanyak 30.0\% (18 responden).

\section{$\underline{\text { Analisis Bivariat }}$}

a. Hubungan Beban kerja dengan Stres Kerja.

Tabel 8. Distribusi Responden Berdasarkan Hubungan Beban Kerja Dengan Stres Kerja Pada Perawat di Ruang Rawat Inap RSUD Kota Namrole Tahun 2020

\begin{tabular}{lcccccccc}
\hline \multirow{2}{*}{$\begin{array}{l}\text { Beban } \\
\text { kerja }\end{array}$} & \multicolumn{9}{c}{ Stres Kerja } & \multicolumn{2}{c}{} \\
\cline { 2 - 7 } & Rendah & \multicolumn{2}{c}{ Sedang } & \multicolumn{2}{c}{ Berat } & \multicolumn{2}{c}{ Total } \\
\cline { 2 - 8 } & $\mathbf{n}$ & $\mathbf{\%}$ & $\mathbf{n}$ & $\mathbf{\%}$ & $\mathbf{n}$ & $\mathbf{\%}$ & $\mathbf{n}$ & $\mathbf{\%}$ \\
\hline Ringan & 18 & 30 & 5 & 8.3 & 0 & 0 & 23 & 38,3 \\
Sedang & 0 & 0 & 15 & 25.0 & 0 & 0 & 15 & 25,0 \\
Berat & 0 & 0 & 4 & 6.7 & 18 & 30 & 22 & 36,7 \\
\hline Total & $\mathbf{1 8}$ & $\mathbf{3 0}$ & $\mathbf{2 4}$ & $\mathbf{4 0}$ & $\mathbf{1 8}$ & $\mathbf{3 0}$ & $\mathbf{6 0}$ & $\mathbf{1 0 0}$ \\
\hline \multicolumn{3}{l}{ Sumber: Data Primer } & 2020 & & & &
\end{tabular}

Tabel 8 tentang hubungan beban kerja dengan stres kerja di ruang rawat inap RSUD Kota Namrole, menunjukkan bahwa perawat dengan beban kerja ringan yang mengalami stres rendah sebanyak 30\% (18 responden) dan beban kerja ringan yang mengalami stres sedang sebanyak 8,3\% (5 responden) dan beban kerja ringan yang mengalami stres berat sebanyak $0 \%$ (0 responden), selanjutnya beban kerja sedang yang mengalami stres rendah sebanyak $0 \%$ (0 responden) dan beban kerja sedang yang mengalami stres sedang sebanyak 25,0\% (15 responden) dan beban kerja sedang yang mengalami stres berat sebanyak $0 \% \quad(0$ responden), selanjutnya beban kerja berat yang mengalami stres rendah sebanyak $0 \% \quad(0$ responden) dan beban kerja berat yang mengalami stres sedang sebanyak $6,7 \%$ (4 responden) dan beban kerja berat yang mengalami stres berat sebanyak 30\% (18 responden). Berdasarkan nilai uji statistik chisquare, diperoleh nilai $p=0,000(p<\alpha=0,05)$. Hal ini berarti Ha diterima dan Ho ditolak, Jadi, terdapat hubungan yang bermakna dari beban kerja dengan stress kerja di ruang rawat inap RSUD Kota Namrole.

b. Hubungan Pendidikan terakhir dengan Stres Kerja.

Tabel 9 tentang hubungan pendidikan dengan stres kerja di ruang rawat inap RSUD Kota Namrole, menunjukkan bahwa perawat dengan pendidikan rendah yang mengalami stres rendah sebanyak 11,7\% (7 responden) dan Pendidikan rendah yang mengalami stres sedang sebanyak 13,3\% (8 responden) dan Pendidikan rendah yang mengalami stres berat sebanyak 30,0\% (18 responden), selanjutnya pendidikan tinggi yang mengalami stres rendah sebanyak 18,3\% (11 responden) dan Pendidikan tinggi yang mengalami stres sedang sebanyak $26,7 \%$ (16 responden) dan Pendidikan tinggi yang mengalami stres berat sebanyak $0 \% \quad(0$ responden).

Berdasarkan nilai uji statistik chi-square, diperoleh nilai $p=0,000(p<\alpha=0,05)$. Hal ini berarti Ha diterima dan Ho ditolak, Jadi, terdapat hubungan yang bermakna dari beban kerja dengan stress kerja di ruang rawat inap RSUD Kota Namrole 
Tabel 9 Distribusi Responden Berdasarkan Hubungan Pendidikan Terakhir Dengan Stres Kerja Pada Perawat Di Ruang Rawat Inap RSUD Kota Namrole Tahun 2020

Stres Kerja

\begin{tabular}{lccccccccc} 
Pendidikan & \multicolumn{1}{c}{ Rendah } & \multicolumn{2}{c}{ Sedang } & \multicolumn{2}{c}{ Berat } & \multicolumn{2}{c}{ Total } \\
\cline { 2 - 8 } & $\mathbf{n}$ & $\boldsymbol{\%}$ & $\mathbf{n}$ & $\boldsymbol{\%}$ & $\mathbf{n}$ & $\boldsymbol{\%}$ & $\mathbf{n}$ & $\boldsymbol{\%}$ \\
\hline Rendah & 7 & 11,7 & 8 & 13,3 & 18 & 30,0 & 33 & 55,0 \\
Tinggi & 11 & 18,3 & 16 & 26,7 & 0 & 0 & 27 & 45,0 \\
\hline Total & $\mathbf{1 8}$ & $\mathbf{3 0 , 0}$ & $\mathbf{2 4}$ & $\mathbf{4 0 , 0}$ & $\mathbf{1 8}$ & $\mathbf{3 0 , 0}$ & $\mathbf{6 0}$ & $\mathbf{1 0 0 , 0}$ \\
\hline
\end{tabular}

Sumber: Data Primer 2020

c. Hubungan Masa Kerja dengan Stres Kerja

Tabel 5.11 tentang hubungan masa kerja dengan stres kerja di ruang rawat inap RSUD Kota Namrole, menunjukkan bahwa perawat dengan masa kerja lama yang mengalami stres rendah sebanyak 18,3\% (11 responden) dan masa kerja lama yang mengalami stres sedang sebanyak 16,7\% (10 responden) dan masa kerja lama yang mengalami stres berat sebanyak 15,0\% (9 responden), selanjutnya masa kerja baru yang mengalami stres rendah sebanyak $11,7 \%$ (7 responden) dan masa kerja baru yang mengalami stres sedang sebanyak 23,3\% (14 responden) dan masa kerja baru yang mengalami stres berat sebanyak $15,0 \%$ (9 responden).

Berdasarkan nilai uji statistik chi-square, diperoleh nilai $p=0,459(p>\alpha=0,05)$. Hal ini berarti Ha ditolak dan Ho diterima, Jadi, tidak terdapat hubungan dari masa kerja dengan stres kerja di ruang rawat inap RSUD Kota Namrole.

Tabel 10 Distribusi Responden Berdasarkan Hubungan Masa Kerja Dengan Stres Kerja Pada Perawat Di Ruang Rawat Inap RSUD Kota Namrole Tahun 2020

\begin{tabular}{|c|c|c|c|c|c|c|c|c|}
\hline \multirow{3}{*}{$\begin{array}{l}\text { Masa } \\
\text { Kerja }\end{array}$} & \multicolumn{6}{|c|}{ Stres Kerja } & \multirow{2}{*}{\multicolumn{2}{|c|}{ Total }} \\
\hline & \multicolumn{2}{|c|}{ Rendah } & \multicolumn{2}{|c|}{ Sedang } & \multicolumn{2}{|c|}{ Berat } & & \\
\hline & n & $\%$ & $\mathbf{n}$ & $\%$ & n & $\%$ & $\mathbf{n}$ & $\%$ \\
\hline Lama & 11 & 18,3 & 10 & 16,7 & 9 & 15,0 & 30 & 50,0 \\
\hline Baru & 7 & 11,7 & 14 & 23,3 & 9 & 15,0 & 30 & 50,0 \\
\hline Total & 18 & 30,0 & 24 & 40,0 & 18 & 30,0 & 60 & 100,0 \\
\hline
\end{tabular}


Hubungan Pendidikan Terakhir dengan Stres $\underline{\text { Kerja. }}$

Berdasarkan nilai uji statistik chi-square, diperoleh nilai $p=0,000(p<\alpha=0,05)$. Hal ini berarti Ha diterima dan Ho ditolak, Jadi, terdapat hubungan yang bermakna dari Pendidikan dengan stres kerja di ruang rawat inap RSUD Kota Namrole.

Hasil ini sejalan dengan penelitian yang dilakukan oleh Mualim ${ }^{13}$ faktor-faktor yang berhubungan dengan stres kerja pada pekerja di kabupaten bengkulu tengah dengan hasil analisis bivariat dengan uji chi-square diperoleh nilai kemaknaan $\mathrm{p}=0,02<0,05$ sehingga dapat disimpulkan bahwa Ha diterima dan Ho ditolak artinya ada hubungan antara tingkat pendidikan dengan stress kerja pada pekerja.

\section{Hubungan Masa Kerja dengan Stres Kerja}

Berdasarkan nilai uji statistik chi-square, diperoleh nilai $p=0,459(p>\alpha=0,05)$. Hal ini berarti Ha ditolak dan Ho diterima, Jadi, tidak terdapat hubungan dari masa kerja dengan stres kerja di ruang rawat inap RSUD Kota Namrole.

Hasil ini sejalan dengan penelitian yang dilakukan oleh Dian Dwiana Maydinar, 2019 dengan nilai uji statistik chi-square, diperoleh nilai $p=0.549(p>\alpha=0,05)$. tidak ada hubngan yang bermakna antara masa kerja dengan stres kerja, Masa kerja yang lama akan cenderung membuat seseorang karyawan lebih merasa

\section{Referensi}

1. Ferrante, D., Cavallero, C., Blas. D. L.,Luis, O.,Filon. L.F., Colautti, L., Marcatto, F. 2016. Work-related stress risk factors and health outcomes in public sector employees. Journal safety science (89), 274-278. betah dalam suatu Tempat kerja, hal ini disebabkan diantaranya karena telah beradaptasi dengan lingkungannya yang cukup lama sehingga seseorang perawat akan merasa nyaman dengan pekerjaannya, masa kerja adalah lamanya seseorang perawat menyumbangkan tenaganya pada tempat kerja tertentu. Sejauh mana tenaga kerja dapat mencapai hasil yang memuaskan dalam bekerja tergantung dari kemampuan, kecakapan dan ketrampilan tertentu agar dapat melaksankan pekerjaannya dengan baik.

\section{Kesimpulan}

Berdaarkan hasil penelitian tentang hubungan stres kerja pada perawat diruang Rawat Inap RSUD Kota Namrole, maka diperoleh kesimpulan bahwa terdapat hubungan beban kerja dengan terjadinya stres kerja pada perawat di ruang rawat inap RSUD Kota Namrole dengan nilai $p=0,000(p<\alpha=0,05)$. Selain itu tidak terdapat hubungan pendidikan terakhir dengan stres kerja pada perawat di ruang rawat inap RSUD Kota Namrole dengan nilai $p=0,000(p<\alpha=0,05)$ dab masa kerja dengan stres kerja pada perawat di ruang rawat inap RSUD Kota Namrole dengan nilai $p=$ $0,459(p>\alpha=0,05)$

2. Febriandini. A. E.,Ma`rufi, I.,Hartanti, I.R. 2016. (Analysis of Individual Factors, Organization Factor and Occupational Fatigue With Work Stress at Nurses (Studies In Inpatient Unit 3rd Grade at General 
Hospitals Dr. $H$ Koesnadi, Bondowoso District) e-Jurnal Pustaka Kesehatan, 4 (1), 175-180. Surabaya.

3. CFO, I. 2016. With Integrated Risk Reporting in Place China's Insurance Industry Continued Strong Growth. CFO Inovation Asian Staff Strategic Intelegence for Finance. Risk Managemen.

4. Timah, E.N. 2014. Analyzing The Influence of Job Stress on Employee Productivity at PT. Bank Tabungan Negara (persero) Tbk Manado. Jurnal Riset Ekonomi, Manajemen Bisnis, dan Akuntansi.Vol.2, No.3. ISSN:2303-1147. Pages.17-59.

5. Ni Wayan Dimkatni, 2020. Apakah Beban Kerja, Stres Kerja dan Kualitas Tidur Mempengaruhi Kelelahan Kerja pada Perawat di Rumah Sakit? Universitas Sam Ratulangi. Fakultas Kedokteran Universitas Sam Ratulangi. Sam Ratulangi Journal of Public Health Vol. 1, No. 1, March 2020

6. Kirana, Vdan E. Dwiyanti. 2017. Hubungan Stress Kerja dengan Kelelahan Kerja pada Perawat dengan Metode Pengukuran Dass 21 dan IRFC. Jurnal Ilmiah Kesehatan Husada. 6(1).

7. Kurnia, HK., N. dan L. Hotmaida. 2015. Hubungan Tingkat Stres Kerja dengan Tingkat Kelelahan Kerja Peraat ICU Rumah Sakit Immanuel Bandung. Immanuel Jurnal Ilmu Kesehatan. 9(1), Juni 2015

8. Febri Ismail, 2020. Hubungan Stres Kerja Dengan Kelelahan Kronis Pada Perawat Di
Ruang Rawat Inap Rsud Wonosari. Stikes Surya Global Yogyakarta .Jurnal Keperawatan, Volume 12, No 1, Januari 2020: 9-18

9. Herqutanto, Harsono, H., Damayanti, M., \& Setiawati, E. P. 2017. Stres Kerja Pada Perawat Di Rumah Sakit Dan Fasilitas Pelayanan Kesehatan Primer. Ejki, Volume 5. Doi: 10.23886

10.Elvinawati, E. 2019. Hubungan Beban Kerja Perawat Dengan Stres Kerja Pada Perawat Pelaksana Di Ruang Rawat Inap Rsud Dr. Moewardi Surakarta. Jurnal Ilmu Kesehatan Universitas Muhammadiyah Surakarta.

11.Hasby, M. 2017. Pengaruh Konflik Kerja, Beban Kerja Dan Komunikasi Terhadap Stres Kerja Komunikasi Terhadap Stres Kerja Perawat Bagian Rawat Inap (Pada Rsud. Petala Bumi Pekanbaru). Volume 4.

12.Yuli Kristyaningsih, 2018. Hubungan beban kerja dengan stres kerja perawat berbasis teori Burnout Syndrome di ruang dahlia RSUD Jombang.

13.Mualim Mualim, Riang Adeko, 2020. Faktor-Faktor Yang Berhubungan Dengan Stres Kerja Pada Pekerja Bagian Dryer Pt. Bukit Angkasa Makmur (Bam) Di Kabupaten Bengkulu Tengah. Politeknik Kesehatan Kementerian Kesehatan Bengkulu, Jurusan Kesehatan Lingkungan. Volume 8 No. 1 (April 2020). The Author(S) 2020. 